\title{
The MNCS Global Ethics And Social Responsibility: A Strategic Diversity Management Imperative
}

Yezdi H. Godiwalla, University of Wisconsin-Whitewater Faramarz Damanpour, James Madison University

\begin{abstract}
A multinational corporation's (MNC) ethical and social responsibility issues must be an integral part of its strategic management process. The MNC headquarters $(H Q)$ must decide on its core ethical and social responsibility values and priorities, and, it should empower its foreign units to formulate their specific programs and strategies to respond to changing host countries' environments.
\end{abstract}

\section{INTRODUCTION}

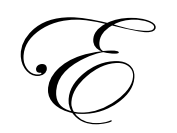

thical and socially responsible conduct of a multinational corporation (MNC) is an important concern in strategic management. Ethical conduct, usually beyond the legal conduct, can be an important requirement for MNCs in most countries. Socially responsible conduct is similarly a most desirable activity. Expectations of both ethical conduct and socially responsible conduct can vary in cultures of different countries. Despite pressures of customizing because of the cultural relativism of ethics and social responsibility, there is a growing need of improved global approach by MNCs on these two dimensions.

An MNC's social and cultural environments, as they change from time to time, should have a bearing on the MNC's ethical and socially responsible conduct. An MNC 's social and cultural environments comprise at three tiers: global, regional and host country. Thus, an MNC must take into account the stakeholders at the three tiers as it formulates core ethical and socially responsible goals and strategies at the levels of MNC headquarters (HQ), region and host country.

The core ethical and socially responsibility values and priorities may be of greater concern for the MNC HQ for a broad global scope. For the foreign subsidiary, the focus would be the more customized application and the detailed strategic and operational processes.

Some ethical and socially responsible values and priorities may be quite common to many countries, particularly if they are culturally close. Even among culturally close countries, the specific interpretation, implementation and priorities of ethics and social responsibility could vary. Ethical and socially responsible conduct is culture bound. Even so, the globalization process increasingly brings countries closer on essential issues; and that tends to make core values for many ethical issues similar. Such issues may be very general, e.g., honesty, fairness, integrity, protecting ecology, meeting and raising industry norms.

\section{DEFINITIONS OF ETHICS AND SOCIAL RESPONSIBILITY}

Ethics are defined as the process of distinguishing the right and good from the wrong and bad, and they imply a moral duty to pursue the good and the right. Business ethics are concerned with the good or right and the bad or wrong behavior in the business context. International business ethics apply to the varying business ethical issues in diverse country cultures. 
Social responsibility is conceptually allied to business ethics. It implies that businesses should act more responsibly, beyond the pure profit or economic motive. It embraces the stakeholder approach and it also concerns the larger society and ecology.

\section{The Purpose Of The Paper}

The purposes of the paper are:

- $\quad$ To emphasize the importance of making ethical and socially responsible issues to be integral parts of the MNC's strategic management process; and

- $\quad$ To provide frameworks that outline the formulation of the overall, broad ethical and socially responsible values, goals and strategies at the MNC HQ level (for the overall MNC), and, the detailed specific strategies at the foreign subsidiary level (for each foreign subsidiary).

The paper stresses the importance of the need to manage and reconcile two opposing forces: (a) the need for a very broad uniform, global ethical and social responsibility approach and standards, and (b) the need for customizing ethical and social responsibility detailed application of the standards, strategies and programs to each country culture.

The paper makes a case for focusing on continuous evolution of the MNC world-view of global social responsibilities to be broader and more universal, viewing the world as a whole society that has very similar general human values, needs and concerns. At the same time, the MNC must allow for country-specific social responsibility programs and activities that are customized to each country's unique circumstances. It is appropriate that at the MNC HQ level, the MNC will develop general core values and priorities to help direct organizational resources world-wide. And, within this general global core values and priorities framework, each foreign subsidiary unit should be empowered to tailor-make its own detailed activities and programs as a continuous response to its host country's changing needs and expectations.

Much of the challenge of the executives of MNC headquarters and foreign subsidiaries is to make proper judgments to pursue an effective ethical and social responsibility strategy, both globally and locally, in view of contradictory pressures (as those outlined in the first paragraph of the following Literature Review section) and in view of resource availability with regard to social responsibilities programs.

\section{Literature Review}

What is acceptable and what is unacceptable is a matter of opinion. Consider this: "There is nothing good or bad but thinking makes it so. Shakespeare, Henry V.”

What we think is good or bad is usually determined by the way we are influenced culturally.

There is a growing awareness of MNCs to better focus on an ethical conduct that goes well beyond the strict legal interpretation. Because of their size, MNCs are usually more conspicuous, and so there is a greater need for a formal ethical code of conduct for its employees. The challenge is to be able to reconcile the contradictory forces of:

- a universal ethical code (i.e., it is possible to have core general values and priorities of preferred ethical conduct);

- $\quad$ cultural relativism (i.e., the need to adapt or customize ethics to local culture);

- $\quad$ competitive pressures (i.e., other companies from other countries pursue a lesser ethical approach in gaining unfair competitive advantage over those companies following stricter ethical standards in doing business).

Much like a rainbow, there are different shades and colors of social responsibility approaches and programs. Scholars provide this range of this spectrum; for example, Armstrong (2003); Asgary and Mitschow (2002); Brady, Crittenden, Hoffman and Robertson (2002); Cottrill (1990); Clikeman (2004); Donaldson (2003); Epstein (1987); Freeman and Gilbert (1988); Freeman and Liedtka (1991); Grant (1991); Kraft and Hage (1990); Salbu (1993); 
Saunders and Thorne (2002); Snider (2003); and Stoffman (1991). Many of these scholars agree that there is a need for ethical and social responsibilities issues management to be integrated in strategic management decision making at the highest level in the organization, that there should be more effective and sustainable social responsibilities programs, and that there is the issue of duality of global versus local considerations for ethical and social responsibilities programs.

There is also the argument that business organizations should go beyond the Milton Friedman tenet that the only responsibility of a business organization is to its shareholders (Grant, 1991). Here it is posited that good social responsibility is good business, that the good will and reputation of ethical and socially responsible organizations will win in the long run and MNCs will earn the public's respect and admiration. pyramid:

Managing stakeholders has been one approach on this topic. And Archie Carroll (1991) sums it up in his

Level 4: $\quad$ Philanthropic responsibilities

Level 3: $\quad$ Ethical responsibilities

Level 2: $\quad$ Legal responsibilities

Level 1: $\quad$ Economic responsibilities

The assumption here is that organizations must continuously achieve very good performance on the first three levels before focusing on the fourth level.

Almost similarly to Maslow's hierarchy of needs, this pyramid focuses on the lower three levels as the basic, necessary organizational performance needs. After the first three (bottom) levels are satisfied, the firm may focus on the top level organizational performance. For instance, a firm must perform economically well if it can sustain social responsibility performance.

It is worthwhile to reiterate the notion that business organizations are social organs with economic and other business goals, and, that they exist in their society. Therefore, they should be responsible to the society which allows them to exist and thrive. This viewpoint is well espoused by Asgary and Mitschow (2002). Further, Freeman and Gilbert (1988, p. 89) provide the reasons why business organizations should go beyond mere economic goal orientation.

They are: "Firms are social entities, and so they should play a role in social issues of today. They should take seriously their 'obligations to society' and actively fulfill them."

One important consideration for an MNC is that its social environment is much more broad and diverse than a more domestically-oriented organization. The challenge is to be at the same time global and local in its socially responsible values, priorities and programs. More importantly, an MNC must feel that it is a part of many societies of many countries in which it has operations. It is indeed a challenge to implement this approach. Freeman and Liedtka (1991, p. 97) express the concept thus:

If we come to see corporations as connected sets of stakeholders, all of whom are 'in it together,' then we are able to live in a way that doesn't carve up the world into 'economic, social, political, and technological' parts.

Also, in this context, the breadth of cultural diversity makes it challenging for formulating and implementing these ethical and social responsibility programs. Wozniak (1997, p. 1) captures the sentiment well:

Business behavior emanates from the complex set of factors that define a culture. These factors include how we perceive the environment, time, power, structures, space; the emphasis we place on relationships or tasks, on individuals or the collective; how we think and communicate. Confucianism focuses on collective order and hierarchy. The social corporatism of Sweden stresses social class and the equality of results. 
From an overall MNC point of view, it becomes more difficult to forge a common set of core social responsibilities values and priorities. And yet the need to develop a viable core set of values and priorities is important. It is a starting point in the process of overall MNC strategic management and for formulating ethical and social responsibilities programs and strategies for different regions and for each host country.

\section{THE MODELS}

The three tables provide the models to achieve the purposes of the paper. Ethics and social responsibility should be an integral part of an MNC's strategic management process. The central theme is that the MNC HQ should seek common core values for the overall organization, provide a framework of formulating priorities of ethics social responsibilities, and empower foreign subsidiaries to customize specific ethical codes of conduct and social responsibility programs.

The three tables provide a conceptual base for a broad global, strategic framework for formulating MNC objectives, goals and strategies, and, for countries' ethical and social responsibility strategies. Within the broad MNC strategic picture, each foreign subsidiary periodically (re-) formulates its goal-mix for the state of its current environment. Based on its current environment, it formulates its corporate strategy and ethical and social responsibility strategy for the current time frame. The MNC HQ and its foreign subsidiaries strive to have a common core of ethical and social responsibility values, and, more customized host country focused ethical and social responsibility programs.

\section{Table 1: Mnc's Global Strategic Management And Foreign Subsidiary's Ethical And Social Responsibilities} Strategies

Table 1 provides the process by which an MNC reviews important social and economic issues (both global and local) as it formulates its overall strategic management issues, including its overall corporate strategy. The next phase is to allow each foreign subsidiary unit to customize its specific social responsibilities programs to the host country's unique needs and circumstances. These programs and strategies would reflect the host country's cultures and social responsibilities needs and expectations.

At the MNC HQ, the overall global strategic management issues that pertain to the overall and global scope of the MNC are important. Considerations such as its position in the industry, markets, regions and society, and, the values for which it stands become important.

An MNC's foreign subsidiaries operate in diverse cultures. Each culture has its unique set of expectations and needs. The lower half of the table provides a logical approach for each subsidiary to customize its local ethical and social responsibility strategies, based upon the local culture's expectations and needs.

\section{Diversity Management Issues}

For an MNC HQ, the challenge of managing a set of culturally diverse populations. The many countries' cultures, with all their different backgrounds, pose management issues, e.g. styles do supervision, policies, decision making process, communication styles. Together, they pose interesting challenges of how to more effectively manage the organizational process. Cultural diversity management becomes the central focus of the MNC HQ, in addition to other organizational HQ focus.

\section{Table 2: A Foreign Subsidiary's Strategic, Ethical And Social Responsibilities Management Process}

Table 2 provides focus on the foreign subsidiary's strategic management process over periods of different time frames. The changing organizational environmental situa tion would make it necessary for a unit to change its ethical and social responsibilities programs and strategies. Changes in social values and priorities in the host country's culture, for example, would make it necessary for the foreign subsidiary to modify its strategies. It is from the analyses of business and societal environment of the host country that the goal-mix of the foreign subsidiary should be formulated for each time frame. The foreign subsidiary's corporate strategy should be derived from the goal-mix. 
And from its corporate strategy, should be derived the detailed ethical and social responsibilities strategies. When the business and societal environments significantly change, then the goal-mix should also change. When the goal-mix changes, corporate strategy should also change.

Table 1: Mnc's Global Strategic Management And Foreign Subsidiaries Ethical \& Social Responsibilities Stratgies

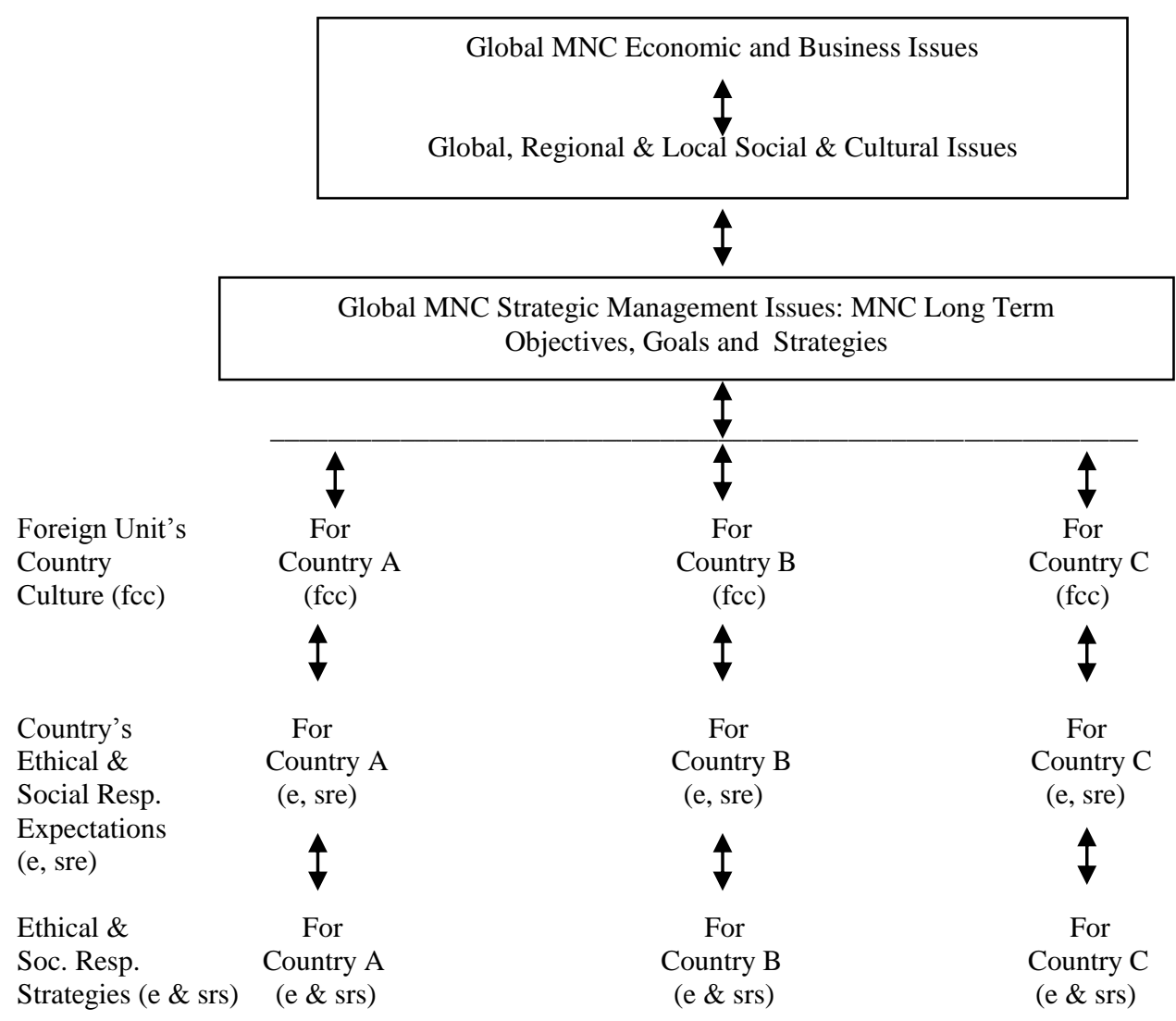

\section{Diversity Management Issues}

As can be seen in Table 2, the business and societal environments of a host country may have culturally diverse stakeholders populations, including suppliers, employees, customers, nearby communities, government and political leaders. Further, as cultural dynamics take place, the foreign subsidiary must manage its varying and changing social make up in terms of customer preference changes, employee attitude changes, HQ management, philosophy changes, and organizational cultural changes with the foreign unit and other nearby foreign units. Thus, (time) longitudinal cultural changes provide an additional dimension of cultural diversity management challenges.

\section{TABLE 3: MNC's Core Global Values And Priorities And Customized Foreign Subsidiary's Detailed Ethical And Social Responsibilities Strategies}

Table 3 embodies the viewpoint of the paper, namely that the MNC HQ should focus on deciding upon core global values and priorities for ethical and social responsibilities issues. Within this broad core set of values and priorities, each region and each foreign subsidiary should develop its own specific social responsibility programs and strategies. 
While the MNC HQ finalizes and shares the core global ethical values and core social responsibility priorities, it is for each foreign subsidiary to apply the general MNC values and priorities to its current local situation. The foreign subsidiary should apply the detailed programs, such as those delineated in the lower box of the table.

In sum, the three tables provide the connection between strategic management and ethical and social responsibility in the context of international business. They tables combinedly provide an organizing conceptual framework for MNC HQ and foreign subsidiaries to simultaneously address the global environments for formulating coherent MNC ethical and social responsibility values, goals and strategies for the MNC as a whole and for the subsidiaries.

Table 2: A Foreign Subsidiary Unit's Strategic \& Ethical And Social Responsibility Management Process

Bus. \& Societal

each time frame

(B \& SE)

Goal Mix for each time frame (GM)

Corp. Strategy

for each time

frame

(CS)

Ethical, Social

Resp. Strategies

for each time

frame (E, SRS)
Environ. for

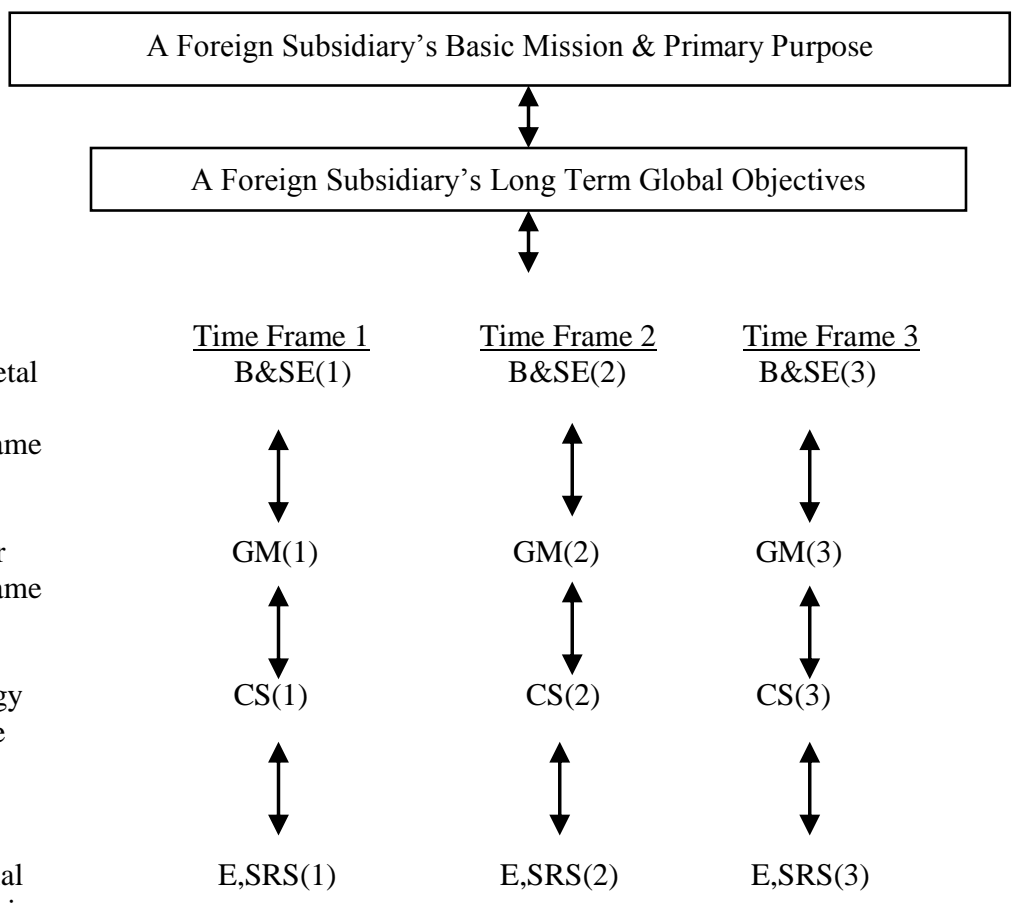

Table 3: Mnc's Core Global Values \& Priorities, And Customozed Foreign Subsidiary's Detailed Ethical \& Social Responsibility Strategies

MNC's Global Perspectives: Core Global Ethical Values and Core Social

Responsibility Priorities

(For each foreign subsidiary unit:)

Customized Detailed Ethical \& Social Responsibility Strategies, e.g.:

- $\quad$ Ethical issues re: bribery, honesty, integrity, accountability, fairness, legal compliance and beyond, fair employment and staffing practices, ecological

- $\quad$ Social responsibilities (need-based) issues re: community-oriented programs, charitable \& philanthropic activities, local and regional developmental, educational and medical activities 


\section{Diversity Management Issues}

While the MNC HQ is concerned with core ethical and social responsibility values, the diverse cultural values and orientations of the many foreign subsidiaries make it further challenging tot the HQ to come up with a common set of values. Diversity issues often make the work of HQ more complex, and challenging and interesting. The broad social responsibility goals and strategies can be just that, broad. The detailed strategies should be left to the foreign unit management.

\section{DISCUSSIONS AND RECOMMENDATIONS}

An MNC's global ethical and social responsibility is an important and integral part of its strategic management process. Ethics and social responsibility is not a choice, but an imperative for an MNC.

Ethical and socially responsible conduct should be the cornerstone of any organization's core values and strategic management process. The process should start with such a conduct as the basis of all strategic management thought. It should be embodied in an organization's basic mission and vision.

For an MNC, ethical and social responsibility charge becomes an imperative because it is globally conspicuous, and, its activities have global impact and ramifications. Thus, an MNC's activities must emanate from an ethically and social responsibly inspired vision and core values. It must lead the charge for industry-wide higher standards, norms and practices. It must be a leader in the industry not only in technology, organizational practices, product features, R\&D, marketing organization and performance, but is must also lead in ethics and social responsibility in its home country and all its other countries.

Pursuit of rapid growth, increased market share and profits, competitive performance and its other commercial activities must be done in consonance with its established core ethical values and socially responsible vision. Growth with ethics is the right way.

Organizational culture at an MNC's HQ and at its foreign subsidiary units must reflect the established core ethical and social responsibility values. If the organizational culture is lagging behind an improved core ethical and socially responsible values, then the organizational leaders must influence to change the organizational culture.

Ethics are culture bound. Different societies place different expectations and priorities on organizations for their ethical and socially responsible conduct. This variability of expectations and priorities set by different country cultures upon an MNC's multiple country subsidiaries indeed poses complexity. An MNC with many subsidiaries or joint venture organizations in many diverse country cultures would expect to customize its detailed ethical and social responsibility strategies for different country cultures. It may choose to have common, global core values regarding ethical and social responsibilities, and, vary its detailed content and process regarding ethical and social responsibilities from one country culture to another. Cultural differences among countries would result in different culturedirected ethical and social responsibilities strategies.

Social responsibility programs can be sustainable, i.e., an MNC can afford them over a period time, only if it is sufficiently profitable. The concept of sustainability is closely tied to the MNC's continuous profitability. Further, the MNC must show a reasonable growth which may be manifested in terms of sales and market share, and profitability, R\&D, product range and applications, expansion of regions, and organizational development. It is more likely that an MNC manifesting these growth attributes will be more likely to pursue, if it wants to, sustainable social responsibility programs. The concept of sustainability is based upon: (a) the ability of the foreign subsidiary to sustain the expense of these strategies, (b) the estimated long term effects and benefits of these strategies, and (c) the relative cost benefit analysis of these strategies. If the assessment of sustainability indicates a good prospective future, then there would be more reasons for furthering and expanding ethical and social responsibility programs and strategies. Organizational growth, environmental munificence, social environmental responsiveness and encouragement, strong and positive impact of social responsibilities programs on the local social fabric, and better communication and coordina- 
tion among organizational members and their extra-organizational linkages tend to reinforce the worthwhileness of these programs, thus providing a likelihood of perpetuating these programs.

A business organization can be here viewed as a social organ with specific business goals and that operates in its host society. It is inevitable for such an organization to focus upon its host society if it is to find support from the host society to allow the business organization to thrive and flourish. Growth and success of a foreign subsidiary similarly depends upon its ability to forge and strengthen organization-environmental linkages in ways that help it to better adjust to the environment and enable it to better address the needs, concerns and expectations of the society of the host country.

It would be beneficial for the foreign subsidiary if it would customize to the core social values of the host country culture(s). Should it find that unacceptable, it can be argued in hindsight that the MNC's entry into the country was not a good strategic move. In this event, the MNC's course of action may be withdrawal from the country. Barring such an action, to the extent feasible within the scope of the MNC's core ethical and social responsibility values, it is important for foreign subsidiaries to accept the host culture's core values. Such a conscious move would better align social responsibility strategies to the more focal needs of the host country societies. Its detailed ethical conduct should similarly be fine tuned to the local cultures, thus making the MNC better accepted by the host country. Should there be the case of the need to maintain higher standards with regard to ethical conduct, it probably would be prudent to do so. This is particularly relevant with issues such as bribery, integrity, honesty, truthfulness and fairness, worker safety and fair employment practices, and ecologically responsible practices.

The cultural divide can pose a difficult challenge for an MNC's HQ when it strives to compose a core set of values and priorities for global ethics and social responsibilities, and, more importantly, when it develops detailed strategies and programs for each host country culture, and plans for implementation. The translation of an MNC's global core set into specific strategies for each host country requires intimate knowledge of the needs and expectations of the host country people. Their culture should become the basis of the foreign subsidiary's foundation for its ethical and social responsibility strategies.

\section{CONCLUSION}

Strategic management premises must be founded upon ethical and social responsibility considerations. Strategic management must evolve from basic social values, needs, expectations and considerations as they can be compatible with an organization's business and economic needs.

Strategic management and ethical and social responsibilities are very closely interrelated. Good strategic management practice is one which is correctly based upon sound ethical and social responsibilities considerations.

It is vital for any organization, more particularly the more global and larger organizations, to integrate core ethical and social responsibility values and goals into the organization's overall strategic management process. Adding them as an afterthought to its corporate strategy is not an acceptable approach because the foundation of any business organization is in its society, local and global.

For an on-going strategic management process, an organization should increasingly focus on sustainable and worthwhile social responsibility programs. Periodic evaluations of the effectiveness of such programs are important, thus making strategic management focus not only on the evaluation of business and economic performance, but also on that of social responsibility programs.

\section{Discussion On Diversity Management}

The issues of diversity management are addressed within the discussion of each table. The MNC HQ must show tolerance, accomodativeness, sensitivity and breadth in managing global diverse cultures. Growth in organizational diversity is inevitable as the MNC business scope and magnitude grows. Diversity intensifies the MNC HQ 
must focus on the broader, more general issues of objectives, goals, policies and strategies as it deals with its global diversity management.

\section{RECOMMENDATIONS}

These are some general recommended guidelines.

- It would be helpful if MNC HQ would take greater lead in coordinating, integrating and communicating the overall core ethical and social responsibility values. In arriving at them it should engage in a participative approach so that there is a clear partnership between the MNC HQ and foreign subsidiaries

- It may be practical to cluster culturally close countries in the process of developing broad core values of the MNC.

- It may be beneficial to generate greater culture rich details in the formulation of detailed ethical and social responsibility strategies for a particular country.

- $\quad$ A process should be set in place that allows for an on-going review and evaluation of the MNC core values and the detailed foreign subsidiary strategies. Such review must include global and local changes and trends in social values, infrastructures, economy, legal aspects, and industry norms.

- $\quad$ The MNC (HQ) CEO, COO and other top management must be directly and actively involved in the process. They must have fuller communication with all foreign subsidiaries' top management.

- $\quad$ The MNC and foreign subsidiary top management must address the issue of sustainability of the ethical and social responsibility strategies and programs so that the organization has a clear plan for the continuity of these programs.

\section{REFERENCES}

1. Armstrong, Mary Beth. (2003) Professionalism and Ethics in Accounting Education. University of Montana.

2. Asgary, Nader \& Mitschow, Mark C. (2002) Toward a Model for International Business Ethics. Journal of Business Ethics, Vol. 36, \#3, 239-246.

3. Brady, Michael K., Crittenden, William F., Hoffman, James J. \& Robertson, Christopher J. (2002) Situational Ethics Across Borders: A Multicultural Examination. Journal of Business Ethics, Vol. 38, \#4, 327-338.

4. Brouthers, Keith D. \& Brouthers, Lance E. (2001) Explaining the National Cultural Distance Paradox. Journal of International Business Studies, Vol. 32, \#1, 177-195.

5. Carroll, Archie B. (1991) The Pyramid of Corporate Social Responsibility: Toward the Moral Management of Organizational Stakeholders. Business Horizons, Vol. 34, 39-48.

6. Clikeman, Paul. (2004) Socially Conscious Corporation: How Can You Reap the Rewards of Good Corporate Citizenry? Strategic Finance, April, 23-35.

7. Cottrill, M.T. (1990) Corporate Social Responsibility and the Marketplace. Journal of Business Ethics, Vol. 9, 723-728.

8. Donaldson, Tom. (2003) Editors Comments: Taking Ethics Seriously - A Mission Now More Possible. Academy of Management Review, Vol. 28, \#3, 363-378.

9. Epstein, Edwin M. (1987) The Corporate Social Policy Process: Beyond Business Ethics, Corporate Social Responsibility and Corporate Social Responsiveness. California Management Review, Vol. 27, 99-111.

10. Freeman, R.E. \& Gilbert, D.R. (1988) Corporate Strategy and the Search for Ethics. Englewood Cliffs, NJ: Prentice-Hall.

11. Freeman, R.E. \& Liedtka, J. (1991) Corporate Social Responsibility: A Critical Approach. Business Horizons, Vol. 34, 92-97.

12. Grant, C. (1991) Friedman Fallacies. Journal of Business Ethics, Vol. 10, 907-913.

13. Kraft, K.L. \& Hage, J. (1990). Strategy, Social Responsibility and Implementation. Journal of Business Ethics, Vol. 9, 12-18.

14. Salbu, S.R. (1993) Corporate Social Responsiveness: Choosing Between Hierarchical and Contractual Control. Journal of Business Ethics, Vol. 12, 27-35. 
15. Saunders, Susan B. \& Thorne, Linda. (2002) The Socio-Cultural Embeddedness of Individuals' Ethical Reasoning in Organizations (Cross-cultural Ethics). Journal of Business Ethics, Vol. 35, \#1, 1-14.

16. Snider, Jamie. (2003) Corporate Social Responsibility in the $21^{\text {st }}$ Century: A View from the World's Most Successful Firms. Journal of Business Ethics, Vol. 48, \#2, 175-186.

17. Stoffman, D. (1991) Good Behavior and the Bottom Line. Canadian Business, 28-32.

18. Wozniak, Lynne. (1997) International Business Ethics: When a Corporate Code of Conduct is NOT Enough. Relocation Journal, July, 1-28. 